BULLETIN (New Series) OF THE

AMERICAN MATHEMATICAL SOCIETY

Volume 43, Number 3, July 2006, Page 397

S 0273-0979(06)01119-0

Article electronically published on April 25, 2006

\title{
ERRATUM TO "LOCAL ALGEBRAS OF A DIFFERENTIAL QUASIGROUP"
}

Local algebras of a differential quasigroup, by Maks A. Akivis and Vladislav V. Goldberg, Bull. Amer. Math. Soc. (N.S.) 43 (2006), 207-226.

There are three places in our paper where "differential quasigroup(s)" should have been "differentiable quasigroup(s)": (1) in the title, (2) in the Abstract, and (3) in the first line on p. 209. We thank those who brought this inaccuracy to our attention.

Department of Mathematics, Jerusalem College of Technology-Mahon Lev, Havaad Haleumi St., P. O. Box 16031, Jerusalem 91160, Israel

E-mail address: akivis@mail.jct.ac.il

Department of Mathematical Sciences, New Jersey Institute of Technology, UniVersity Heights, New Jersey 07102

E-mail address: vlgold@oak.njit.edu 